\title{
The Study on Education Equalization in Chinese Ethnic Regions Along the Border; Taking Dehong Prefecture of Yunnan as an Example
}

\author{
Wang Zhi-hui* Ni Lin-lin \\ Yunnan University of Finance and Economics, P. R. China,650221 \\ (328608635@qq.com, 276533117@qq.com)
}

\begin{abstract}
The equalization of education opportunity is the most basic requirements of education equality. It plays an important role in promoting national economic and social development. To achieve education equalization is the common objective of all developed countries and developing countries, but for developing countries, realizing education equalization also exist a series of problems. In Dehong prefecture of Yunnan province, the border area where ethnic groups and overseas Burmese population dominated, the local government has vigorously pursued the nine-year compulsory education, at the same time, the citizen treatment to foreigners are also provided, which greatly promoted the social stability and development in border areas. But since Dehong's economic development is still backward, weak financial capability and incomplete polies, Promoting education equalization still has a lot of problems to solve, such as teachers are poor quality and low salary.
\end{abstract}

Keywords: Dehong prefecture; education equalization; ethnic area; border

\section{Introduction}

Education is treated as the most basic and essential part of the people's career. The growth of a country's education plays a major role in the development of the country's economic and society. Such a big developing country as China, the problem of education equalization is the key of the education. For the frontier ethnic areas which the level of social and economic development lagging behind compared with other regions, the process of promoting educational equalization plays the role of a stabilizer.

\section{Literature review}

Education equalization is that every school-age children regardless of their gender, age, race, occupation, residence, income level, can equally enjoy basic education services. Education equalization which means through the use of public power and education resources, government provides public products and services to meet the demand of the lowest level of society and finally guarantees equal consumption of citizen education. It has different standards at the different stages. It's from the view of dominant education resources that education equalization is discussed[1]. Scholar Dai Wenliang thought equal basic education services are not on the average, but a kind of fairness system arrangement. It is one aspect of the education fair, and it provides a feasible path of practice for the realization of education fairness[2]. Lu Xiaoxiang found out the cause of the problem through the research on the present situation of our public equalization problem, $\mathrm{He}$ also proposed the countermeasures to solve the problem of education equalization. [3]Lou Shiqiao also analyzed the basic education in western ethnic areas, and found out that education equalization cannot copy the practice mode of the town, and it should make an adjustment to the strategy of education equalization[4]. Huang Dongsheng, put forward some suggestions for the balanced development of the compulsory education in ethnic areas: first, the pursuit of individuality characteristic connotation in educational philosophy; Second, the pursuit of the education to fit the development of each student in educational goal; Third, the quality of education to set up scientific 
quality to promote the all-round development of students[5].

From what has been discussed above, we can see, there are a lot of literatures from theory and practice, which discussed the connotation of education equalization, the problems, reasons and the path to achieve equal education. But in the cross-border ethnic areas, the research on education equalization is less. In the background of Dehong prefecture, this article mainly discussed the problem of education equalization in the border ethnic areas, as well as the countermeasures and suggestions to solve those problems.

\section{Taking Dehong prefecture of Yunnan as an} example.

\subsection{The present education situation in Dehong prefecture}

The educational undertaking in Dehong prefecture was quite draggled before China's liberation, and most people were illiteracy. After liberation, complete education system has been started to construct. With the implementation of the three-year plan in recent years, more than 90 private kindergartens have been built, and carried out the free education plan in compulsory education stage. The country and the whole province invested heavily in the career of compulsory education in Dehong prefecture, which includes providing subsidy and nutrition foods, etc. Due to limited financial capacity of local governments, the number of high schools grew slowly. The phenomenon that foreign students come to study in Dehong prefecture has become widespread under the influence of geographical location in Dehong prefecture. Until 2013, there were 3300 foreign students have studied in Dehong prefecture. Local governments in Dehong prefecture took these Burmese students as their local students, they can also enjoy the free education plan in compulsory education stage as well as the subsidy, nutrition foods, etc. All students get along well no matter their different nationalities. This makes the outstanding cross-border ethnic education features in Dehong prefecture[6].

\subsection{The achievements in the field of education in Dehong prefecture}

The local government increased the education investment in the area year by year, including the building construction of primary and secondary schools and institutions of higher learning as well as the school laboratory and other hardware facilities gradually. At the same time, in order to push forward the nine-year compulsory education, Local government promulgated the policy called "Three Exemptions and Two Subsidies"(which means free charge for tuitions and providing textbook and school accommodation freely, subsidies for living expenses and travel expenses). The local government provides more educational opportunities for students in China and Myanmar. In addition, more and more Burmese students study in China under the preferential policies. This performance in the Yingjiang county and WanDing city are more apparent. And the outstanding achievement is now Burmese students should be brought into the normal management in local education system.

\section{The problem of pursuing the education equalization}

\subsection{Insufficient funding for education equalization}

Education accounts for the proportion of financial expenditure in 2009 from $15.2 \%$ to $14.8 \%$ of the 2012, indicating that the lower investment on education is still a crucial problem in pursuing the education equalization. Even though the expenditure 
on basic education has been increased year by year in recent four years, the local government has lower fiscal resource and could not provide financial support education fees for any more Burmese students, including compulsory education and high education.

\subsection{Ethnical teachers are poor quality and low} salary

Most ethnic areas in southwest China are poordeveloped and many good school teachers dislike to teach here. The shortage and imbalances of teachers in the school are serious, especially the lack of bilingual teachers, many local-language-based courses could not be offered. This situation is not only harmful for the protection of the minority traditional culture, but also affecting the heritage of diversity of human culture [7].

\section{Suggestions on education equalization in} Dehong prefecture

\subsection{Increasing education investment and providing} more education opportunities.

Enhancing education investment, increasing teacher's salary and employing performance measures are basic approaches to improve education equality. Local governments should strongly support and encourage different private sectors to establish new schools in order to resolve the financial shortcoming. At the same time, the central government should provide more special grants to ensure "three exemption and two subsidy" into practice without any problems in ethnic areas[8].

\subsection{Improving the quality of teacher team}

Local government should invest more education funds to improve the quality of teacher teams, which has a great significance of ethnic stability in ethnic areas. Because of low standard of payment, there is less people or volunteers who wanted to teach and live here, which caused poor quality of teaching for local students. In order to solve this problem, the head of Wanding School created a prize which is called "Couple Award" to encourage the couples to teach and stay here.

\section{Conclusion}

In summary, education equalization is regarded as an important part of the equalization of public service. However, to achieve education equalization for our country is still a problem. It reflected the problems in the equalization of education opportunities, imbalance of education resources allocation and inequality on education results which are still need to solve. Chinese central government need to set up a special fund to increase the supports, so that it actively promotes the education equalization. Our government especially needs to strengthen the development of compulsory education in ethnic areas, improve teacher's quality in primary and secondary schools. The local government should increase the education funding to provide financial assistance for poor students, and to enhance the level of education equalization in cross-border ethnic regions. It is a good way to cultivate local nationality culture and accelerate the stability in the border region.

\section{Acknowledgement}

This research was financially supported by the Foundation of Ministry of Education, China (NO. 13YJA630096).

\section{References}

(1) Zhang Chao-qiang (2010).The urban and rural compulsory education even equalization studies from the perspective of distribution of education 
resources. Chongqing University Press, 2010, 4.

(2) Dai Wen-liang (2013). The basic equal education services in national regions and their path to explore. Xinjiang social sciences forum, 2013(2).

(3) Lu Xiao-xiang (2010). The study on the problems and countermeasures of public education equalization. China Academic Journal Electronic Publishing House, 2010:199-207.

(4) Lou Shi-qiao (2013). Recognition on the equalization of public equal services-taking basic education as an example. Journal of Hubei University for Nationalities (Philosophy and Social Sciences). 2013(3).

(5) Huang Dong-sheng. (2012). Compulsory education balanced development in ethnic regions of the direction in the future. Ethnic Education in China, 2012(6).

(6) Yu He-nan,,Lei Chen. (2011). The facts, experiences and prospects of education equalization in China-Taking Chengdu as an example. Journal of Hubei University for Nationalities (Philosophy and Social Sciences).2011,11(1).

(7) Qi Jing-yu. (2011). Promoting the equalization of education opportunities and educational equality: Preliminary thinking on the development of compulsory education in ethnic areas Journal of Research on Education for Ethnic Minorities, 2011(3).

(8) Lu Juan (2008).. The study on ethnic education of Dai and Jingpo nationalities in Dehong. Yunnan Normal University. 